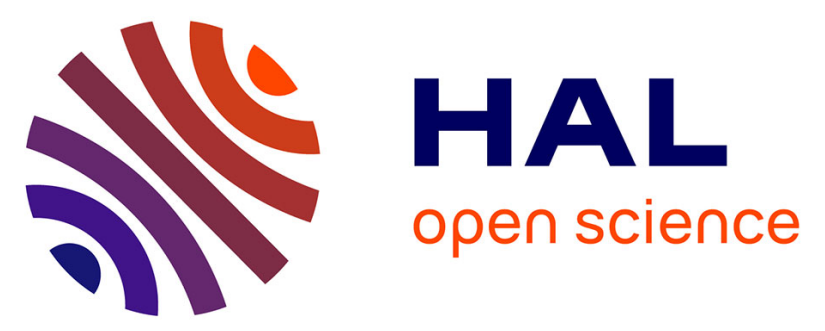

\title{
Taking the Well-being of Future Generations Seriously: Do People Contribute More to Intra-temporal or Inter-temporal Public Goods?
}

\author{
Gilles G. Grolleau, Angela Sutan, Radu Vranceanu
}

\section{To cite this version:}

Gilles G. Grolleau, Angela Sutan, Radu Vranceanu. Taking the Well-being of Future Generations Seriously: Do People Contribute More to Intra-temporal or Inter-temporal Public Goods?. 2013. hal-00866970

\section{HAL Id: hal-00866970 \\ https://essec.hal.science/hal-00866970}

Preprint submitted on 27 Sep 2013

HAL is a multi-disciplinary open access archive for the deposit and dissemination of scientific research documents, whether they are published or not. The documents may come from teaching and research institutions in France or abroad, or from public or private research centers.
L'archive ouverte pluridisciplinaire HAL, est destinée au dépôt et à la diffusion de documents scientifiques de niveau recherche, publiés ou non, émanant des établissements d'enseignement et de recherche français ou étrangers, des laboratoires publics ou privés. 


\title{
Taking the Well-being of Future Generations Seriously: Do People Contribute More to Intra-temporal or Inter-temporal Public Goods?
}

\author{
Research Center \\ ESSEC Working Paper 1313
}

2013

Gilles Grolleau

Angela Sutan

Radu Vranceanu 


\title{
Taking the Well-Being of Future Generations Seriously: Do People Contribute More to
}

\section{Intra-temporal or Inter-temporal Public Goods?}

\author{
Gilles Grolleau $^{(\mathrm{a}}$, Angela Sutan $^{(\mathrm{b}}$, Radu Vranceanu $^{(\mathrm{c}}$
}

a) LAMETA, UMR 1135 and LESSAC, 2 place Viala, 34060 Montpellier Cedex 1. E-mail: grolleau@ supagro.inra.fr

b) LESSAC, 29 rue Sambin, BP 50608, 21006 Dijon Cedex. E-mail :angelasutan@escdijon.eu

c) ESSEC Business School and THEMA, BP 50105, 95021 Cergy, France. E-mail: vranceanu@essec.fr

$$
\text { 25-09-2013 }
$$

\begin{abstract}
We investigate the dynamics of cooperation in public good games when contributions to the public good are immediately redistributed across contributors (intratemporal transfers) and when contributions to the public good by the current group are transferred over time to a future group (inter-temporal transfers). We show that people are more cooperative in inter-temporal contexts than in intra-temporal contexts. We also find that subjects invest more on average in public goods when they know in advance their inheritance from the past.
\end{abstract}

JEL Classification: C72, C92, H41.

Keywords: Public goods, Voluntary contribution mechanism, Inter-temporal vs intratemporal transfers, Sustainable development.

\section{'We do not inherit the earth from our ancestors; we borrow it from our children' (Saint-Exupéry)}

\section{Introduction}

Environmental problems frequently affect current generations and future generations. For instance, contaminated foodstuffs are likely to affect the health for people living nowadays, while long-lived radioactive waste can generate a huge threat for future generations. While the first kind of problems is hard to solve, the second type seems even more difficult to fix. A common prerequisite to address these challenges is altruism, both intra-generational and inter-generational. Indeed, meeting the challenges of sustainable development includes the obligations of not "compromising the ability of future generations to meet their own needs". Addressing the problem of future generations by establishing a cooperative, intergenerational altruism is generally considered as a vexing puzzle. 
Rather than discussing whether individuals have a moral duty or obligation to make sacrifices to ensure the continued existence of the human race, we adopt an empirical approach to investigate the dynamics of cooperation in a public good game under two main treatments, namely when (i) contributions to the public good are immediately redistributed across contributors (standard public good game, intra-temporal transfers) and when (ii) contributions to the public good by the current group benefit not the current group but are transferred over time to a future group (inter-temporal transfers). Thus, at any period, participants can contribute to a public good and their investment will benefit to "the next generation", but they also receive the benefit of the investment in the public good from the "preceding generation".

This experimental design aims to replicate, in a simplified Lab context, the logic of environmental decisions. In short, we examine whether people are more cooperative in intratemporal contexts than in inter-temporal contexts. Given that inter-temporal contexts reinforce the anonymity of players, traditional analysis predicts a lower level of contribution in the inter-temporal context. Surprisingly, our main finding is that people contribute more to a public good in an inter-temporal setting than in an inter-temporal setting. Our findings can be considered as preliminary good news for those concerned by sustainable development, insofar as they reveal existence of some form of intergenerational altruism.

\section{Literature overview and main hypotheses}

There is a sizeable literature on public good games which has shown that contributions are relatively high in one-shot games, but decline over time in finitely repeated public good games (e.g., Ledyard, 1995; Holt, 2007; Chaudhuri, 2011). These robust results have been explained by various mechanisms such as commitments, reciprocity and altruism (e.g., Croson, 2007). The use of transfers over time in a public game was introduced by Cadigan et 
al. (2011) who developed a repeated two-stage PG game with carryover. ${ }^{1}$ They showed that when increasing the carryover effect, the average contribution at the first stage increases.

Unlike their paper, where the contribution investment at time $t$ benefits to the same group at time $(t+1)$, we introduce transfers over time, but these transfers benefit to another group, not to the initial group. Also, individuals benefit from transfers achieved by individuals belonging to another group at time $(t-1)$. This allows us comparing intra-temporal with inter-temporal transfers. Given that inter-temporal transfers increase anonymity among players, our main behavioral hypothesis predicts a lower level of contribution in intertemporal settings $\left(\mathrm{H}_{1}\right)$. This hypothesis is consistent with several studies emphasizing that anonymity reduces voluntary contributions (Rege and Telle, 2004; Andreoni and Petrie, 2004; Alpizar et al., 2008).

We also examine (i) the effects of having or not information on inheritance before deciding how much to contribute and (ii) the impact of the initial endowment on the contribution paths over time. These variations allow exploring two related hypotheses. First, we hypothesize that getting information about the amount inherited before contribution decisions (ex-ante information)shapes contribution to public goods when compared to contribution levels with information revealed after contribution decision (ex-post information) $\left(\mathrm{H}_{2}\right)$.Second, we investigate whether differences in the initial endowment affect subsequent contribution levels. We predict that past contributions establish a reference point that will affect contribution levels today (Ledyard, 1995). More precisely, we expect that high (respectively low) initial endowments are associated with higher (lower) levels of

\footnotetext{
${ }^{1}$ In a first stage, subjects in a group of four can contribute to a public good. The endowment at the second stage is a linear function of gains earned at the first stage. Depending on the treatment, the carryover coefficient is either large $(0.5)$ or small $(0.3)$. The procedure is repeated five times. The group composition does not change from one round to another.
} 
contribution $\left(\mathrm{H}_{3}\right)$. These hypotheses are consistent with theoretical (Bernheim, 1994) and available empirical evidence (Alpizar et al., 2008).

\section{Experimental design}

The experiment was performed at the LESSAC Experimental Lab in Dijon and the ESSEC Experimental Lab in Cergy, in November 2012, with a total of 170 participants. Subjects were recruited from the student population of the schools, who answered to a call for paid decision experiments. The experiment uses a standard between-subjects design, with seven treatments.

At the beginning of the experiment, subjects are randomly matched in groups of five anonymous players. All decisions were made on a computer screen. Instructions and data collection are computerized. ${ }^{2}$ All the payoffs are denominated in Experimental Currency Units (ECU), converted in euros at the end of the experiment, at the exchange rate 100 ECUs $=1$ euro. Subjects were informed that their reward from the experiment depends on their own decision and the decision of their partners. Individuals were asked to play a public good game (hereafter PG) for 10periods. In all treatments, groups were re-matched after each period in a typical "stranger" PG design (Fehr and Gachter, 2000).

The first treatment $\left(\mathbf{T}_{\mathbf{1}}\right)$ is the intra-temporal setup: all decisions and payoffs belong to the same period $t$. At the beginning of each period, every subject gets 40 ECUs. In each period, subjects can invest a positive amount $v$ in a PG, with $v \leq 40$. One ECU invested provides all other members of the group with $0.5 \mathrm{ECU}$ in the same period. ${ }^{3}$ Also, the individual $i$ gets $0.5 \mathrm{ECU}$ for any ECU invested by any of the other four players. In period $t$, the gain of one individual $i$ in a group of five is thus:

$$
\pi_{i t}=40+R_{i t}-v_{i t}, \text { for } t=1 \ldots 10 \text {. }
$$

\footnotetext{
${ }^{2}$ The computer program was developed in z-Tree (Fischbacher, 2007) by Delphine Dubart at the ESSEC Experimental Lab. ${ }^{3}$ At difference with a "classical" PG, the individual has no marginal benefit from his own investment.
} 
Where $R_{i t}$, the income she/he receives from the four other contributors to the PG, is given by:

$$
R_{i t}=0.5 \sum_{j=1 ; j \neq i}^{4} v_{j t}
$$

Subjects are informed about their total gain after each period.

At the Nash equilibrium each subject would get 40 ECUs per period; in the cooperative solution (all invest all their endowment in the PG), each subject can get 80 ECUs.

The other treatments $\left(\mathrm{T}_{2 \mathrm{a}}, \mathrm{T}_{2 \mathrm{~b}}, \mathrm{~T}_{2 \mathrm{c}}, \mathrm{T}_{3 \mathrm{a}}, \mathrm{T}_{3 \mathrm{~b}}, \mathrm{~T}_{3 \mathrm{c}}\right)$ analyze the inter-temporal decision. Treatments $\mathrm{T}_{2}$ and differ with respect to the information structure: either they receive information before $\left(\mathrm{T}_{2}\right)$ or after $\left(\mathrm{T}_{3}\right)$ making their decisions. Subscripts $a, b$ and $c$ indicate variations of the initial endowment.

Table 1 reports the plan of experiments. One session typically lasted less than one hour, including instructions, verification questions and payment.

Table 1. Plan of experiments, treatments and number of subjects per treatment

\begin{tabular}{lccccccc}
\hline & Intra-temporal & \multicolumn{5}{c}{ Inter-temporal } \\
\hline Information & - & \multicolumn{4}{c}{ After own decision } & \multicolumn{3}{c}{ Before own decision } \\
Initial payoff & - & 0 & 40 & 80 & 0 & 40 & 80 \\
Treatment & $\mathrm{T}_{1}$ & $\mathrm{~T}_{2 \mathrm{a}}$ & $\mathrm{T}_{2 \mathrm{~b}}$ & $\mathrm{~T}_{2 \mathrm{c}}$ & $\mathrm{T}_{3 \mathrm{a}}$ & $\mathrm{T}_{3 \mathrm{~b}}$ & $\mathrm{~T}_{3 \mathrm{c}}$ \\
Number of subjects & 20 & 20 & 20 & 30 & 20 & 30 & 30 \\
\hline
\end{tabular}

More precisely, in the inter-temporal setting, in each period, subjects can invest any amount $v \in[0 ; 40]$ in a PG. One ECU invested at period $t$ by an individual $i$ will provide at the next period $(t+1)$ all members of his new group with 0.5 ECU. Also, at time $t$, the individual $i$ benefits from the investment in PG made at the previous period $(t-1)$ by all the members of his current group (in $t$ ). Subjects further receive an endowment of 40 ECUs at the beginning of each period, and they know this.

Obviously, the first period $(t=1)$ cannot be defined in the same way as the subsequent periods since there is no "previous generation". In order to launch the simulation, we thus create an "artificial previous generation", by providing the first generation with an exogenous 
"initial endowment" $A_{k}$. We will study three distinct situations, corresponding to a low, an intermediate and a high initial endowment $A_{k}$, with $A_{a}=0, A_{b}=40$ and $A_{c}=80$. The intermediate (respectively high) endowment could correspond to a generation that plays the noncooperative Nash equilibrium strategy (respectively, the cooperative strategy).

We denoted the individual contribution to the PG by $v_{\mathrm{t}}$. The gain of one individual $i$ at period $t$ can be written as:

$$
\pi_{i t}=40+R_{i t}^{t-1}-v_{i t}
$$

where the income he gets from the past contributions $R_{i t}^{t-1}$ is given by:

$$
R_{i t}^{t-1}= \begin{cases}A_{k}, \quad k=(a, b, c), & \text { for } t=1 \\ 0.5 \sum_{j=1 ; j \neq i}^{4} v_{j, t-1}, & \text { for } t=2,3, \ldots, 10\end{cases}
$$

We also introduce some variations in the information structure of the inter-temporal transfer game. In all $\mathrm{T}_{2 \mathrm{k}}$ treatments, subjects are informed about the amount they receive from the past investment in public good by the previous generation after they make their own decision on how much to contribute to the public good. Even for the first period $(t=1)$, the participants know that they will receive an extra amount, but do not know how much. It is likely they anchor their expectations around the known amount of 40 ECUs. Subjects are also informed about their total gain after each period. In all $\mathrm{T}_{3 \mathrm{k}}$ treatments subjects are informed about the amount they receive from the previous generation at the beginning of the period, before making their own decision. 


\section{Results}

\subsection{Basic statistics}

Table 2 reports average contributions per treatment and period (from $\mathrm{P}_{1}$ to $\mathrm{P}_{10}$ ).

Table 2. Average contribution per treatment and period

\begin{tabular}{lccccccccccc}
\hline & $\underline{\mathbf{N}}$ & $\underline{\mathbf{P}_{1}}$ & $\underline{\mathbf{P}_{2}}$ & $\underline{\mathbf{P}_{3}}$ & $\underline{\mathbf{P}}_{4}$ & $\underline{\mathbf{P}_{5}}$ & $\underline{\mathbf{P}_{6}}$ & $\underline{\mathbf{P}}_{7}$ & $\underline{\mathbf{P}_{\mathbf{8}}}$ & $\underline{\mathbf{P}_{9}}$ & $\underline{\mathbf{P}_{10}}$ \\
\hline $\mathbf{T}_{\mathbf{1}}$ & 20 & 12.20 & 11.95 & 9.75 & 8.55 & 7.95 & 7.00 & 5.20 & 3.50 & 3.20 & 2.45 \\
$\mathbf{T}_{\mathbf{2 a}}$ & 20 & 18.20 & 16.65 & 17.35 & 17.60 & 16.10 & 12.00 & 13.25 & 11.15 & 9.50 & 9.45 \\
$\mathbf{T}_{\mathbf{2 b}}$ & 20 & 16.50 & 19.70 & 17.10 & 13.80 & 14.40 & 13.45 & 16.35 & 15.10 & 10.50 & 10.40 \\
$\mathbf{T}_{\mathbf{2 c}}$ & 30 & 19.63 & 27.23 & 23.37 & 24.20 & 15.43 & 16.23 & 16.30 & 12.37 & 12.93 & 8.37 \\
$\mathbf{T}_{\mathbf{3 a}}$ & 20 & 21.35 & 23.90 & 24.15 & 22.20 & 20.30 & 21.90 & 22.40 & 22.50 & 16.90 & 15.95 \\
$\mathbf{T}_{\mathbf{3 b}}$ & 30 & 21.70 & 14.93 & 14.63 & 13.57 & 14.30 & 8.07 & 9.20 & 6.20 & 5.60 & 7.83 \\
$\mathbf{T}_{\mathbf{3 c}}$ & 30 & 23.10 & 21.90 & 21.03 & 19.20 & 16.83 & 17.63 & 16.27 & 17.43 & 17.90 & 12.40 \\
\hline
\end{tabular}

At first glance, we obtain the standard result documented in the literature, i.e., the average amount invested (cooperation) declines over time in all treatments. However, if we calculate the maintenance rate of individual contributions as $\left(v_{\mathrm{t}} / v_{\mathrm{t}-1}\right)$ (how much of the contribution in period $t-1$ persists in period $t$ ), we obtain an average of 0.84 for $\mathrm{T}_{1}$ (with no values higher that 1), and an average of 0.94 , which is significantly higher, for treatments $T_{2 k}$ and $T_{3 k}$. This clearly indicates that contributions are more likely to be maintained in inter-temporal settings, after having initiated the mechanism.

$\boldsymbol{R}_{1}$ : While declining, contributions are more resilient over time in the inter-temporal settings as compared to the intra-temporal setting.

Figure 1 displays the contributions over time for all treatments (see also Table 2). It turns out that amounts invested in the inter-temporal setup $\left(\mathrm{T}_{2 \mathrm{k}}\right.$ and $\left.\mathrm{T}_{3 \mathrm{k}}\right)$ are systematically higher than in $\mathrm{T}_{1}$. 
Figure 1. Contributions over time (average)

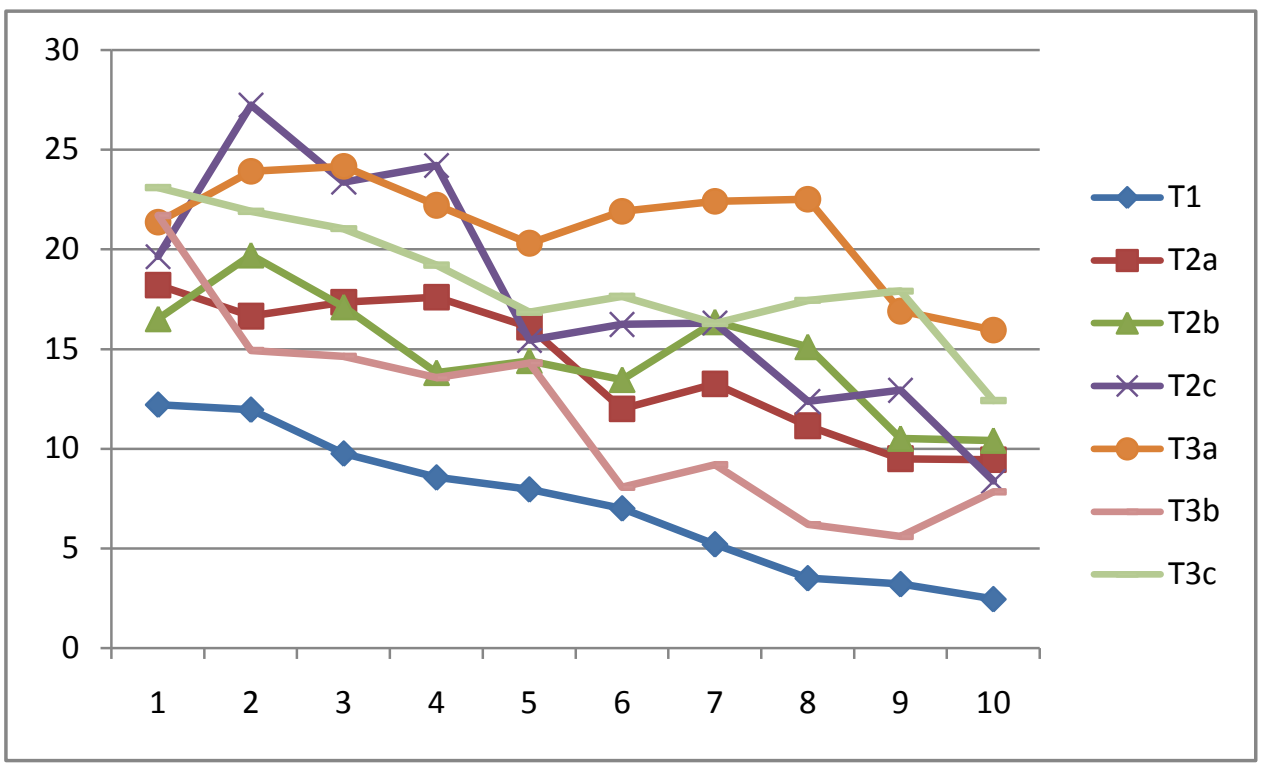

$\boldsymbol{R}_{2}: H_{1}$ is not supported. Contributions are systematically higher in the inter-temporal setting as compared to the intra-temporal setup.

We further observe that first period contributions (P1) start at a higher level in inter-temporal treatments $\mathrm{T}_{2 \mathrm{k}}$ and $\mathrm{T}_{3 \mathrm{k}}$ compared to the intra-temporal treatment $\mathrm{T}_{1}$ (the difference is significant at $p<0.001)$. It also turns out that the average contribution is much lower under the ambiguity specific to $\mathrm{T} 2$ as compared to the certainty characterizing the T3 situations. ${ }^{4}$ Furthermore, in treatment T3 where the "inherited" endowment $A_{\mathrm{k}}$ is known prior to the decision, the larger the endowment, the larger the average contribution. These results provide support to the hypotheses $\mathrm{H}_{2}$ and $\mathrm{H}_{3}$.

\subsection{Regression analysis: the inter-temporal setting}

A panel data analysis can provide additional insights about the inter-temporal decision (T2 and T3). The main dependent variable is the contribution of individual $i$ at period $t, v_{\mathrm{it}}$. We

\footnotetext{
${ }^{4}$ Recall that in T2, investors have no idea about the "bequest from the past" that will add to the 40 ECUs. In T3, this amount is known before decision making (it is either 0,40 or 80 ).
} 
use situation $(a)$ or $\left(\mathrm{A}_{\mathrm{k}}=0\right)$ as a benchmark and create dummy variables for situations $(b)$ and (c), denoted by SIT $b$ and SIT $c$.

The key independent variable is the income the individual receives from the past, $R_{i t}^{t-1}$. We also use as independent variables the situation dummies, and the round $t$. The estimated equation is thus:

$$
v_{\mathrm{it}}=\alpha_{1} R_{i t}^{t-1}+\alpha_{2} \mathrm{SITb}_{\mathrm{it}}+\alpha_{3} \mathrm{SITc}_{\mathrm{it}}+\alpha_{4} \mathrm{t}+u_{\mathrm{i}}+e_{\mathrm{it}}
$$

where $u_{\mathrm{i}}$ is the individual specific error term and $e_{\mathrm{it}}$ is the "standard" error term.

Table 4 provides the output of the Random Effects estimation model..$^{5}$ The first column indicates the coefficients for the whole sample (170 subjects) that played the intertemporal transfer game, both under the "information after decision" treatment (T2) and the “information before decision" treatment (T3); the second column provides estimates only for $\mathrm{T} 2$, the last column the estimates for T3 only.

Table 4. Regression Estimates. Dependent variable: individual contribution

\begin{tabular}{lccc}
\hline \multirow{2}{*}{ VARIABLES } & All & T2 & T3 \\
& Data & contribution & contribution \\
\hline & & & \\
& $-1.066^{* * *}$ & $-1.255^{* * *}$ & $-0.950^{* * * *}$ \\
$\mathrm{SIT}_{\mathrm{b}}$ & $(0.0833)$ & $(0.130)$ & $(0.127)$ \\
& -1.355 & 0.628 & $-8.788^{* * *}$ \\
$\mathrm{SIT}_{\mathrm{c}}$ & $(1.875)$ & $(2.619)$ & $(3.145)$ \\
$\mathrm{R}^{\mathrm{t}-1}$ & $3.244^{*}$ & 3.552 & -2.967 \\
& $(1.803)$ & $(2.416)$ & $(3.132)$ \\
& $0.0387^{* *}$ & -0.00461 & $0.0578^{* * *}$ \\
& $(0.0152)$ & $(0.0241)$ & $(0.0216)$ \\
Observations & $(1.457)$ & $(2.177)$ & $(2.739)$ \\
Number of subjects & & & 800 \\
\hline Standard errors are reported in brackets $/ * * * \mathrm{p}<0.01, * * \mathrm{p}<0.05, * \mathrm{p}<0.1$. & 80 \\
\hline
\end{tabular}

We can see that $\alpha_{4}$ is negative and significant: for all treatments, contributions decline over time, as in any PG standard game. However, for $\mathrm{T} 3, \alpha_{1}$ is positive and statistically significant; when individuals know how much they receive from the past, this "inheritance" provides a

${ }^{5}$ Fixed Effects estimates lead to similar results. 
positive motivation to contribute to the gain of the "next generation". In other words, past transfers create the incentive to transfer toward the next generation, as if the power of example creates a positive anchoring of what is "good". However, in this simple experiment, this form of intertemporal reciprocation does not allow to offset the overall reduction in contributions over time, but only to attenuate it.

When individuals do not know how much they receive from the past, this motivation disappears; $\alpha_{1}$ is not significant in T2. This result is consistent with the common recommendation to communicate on past efforts made to preserve the environment, which can serve as an anchor or as an implicit social norm.

Most coefficients related to situation dummies are not significant, as if our limited variations in the initial endowment have no significant impact on the subsequent decisions to contribute to the public good. We do not have a plausible explanation to the negative coefficient of SITb in the T3 treatment.

\section{Discussion and conclusion}

Contrary to our main hypothesis, there is less coordination in the intra-temporal treatment compared to the inter-temporal treatments. If we contend that an inter-temporal setting is more prone to anonymity than an intra-temporal one, it seems that more anonymity increased contributions. Interestingly, Andreoni and Petrie (2004) also had a treatment where subjects had the option to remain anonymous and this treatment generated the highest level of contributions. This anonymity 'power' is also reported in Hugh-Jones and Reinstein (2011).

In fact, contributing more in inter-temporal treatments than in the intra-temporal treatment can be related to a recent strand of literature about should (oriented towards others, towards what is morally acceptable) rather than want choices (oriented towards self, towards immediate satisfaction). Indeed, Zauberman and Lynch (2005) found that, on average, 
respondents reported being more likely to donate time to charity (a should behavior) in two weeks than tomorrow. In the same vein, Rogers and Bazerman (2008) found that people are more likely to support should policies when those policies will be implemented in the distant future rather than in the near future. In the same vein, Kivetz and Tyler (2007) found that a distant (immediate) future is more likely to activate the idealistic (pragmatic) self and subsequent choices.

Moreover, it is possible that the intra-temporal setting activates more the dimension of an "economic computation" (own benefits), whereas inter-temporal settings activate more the "moral" dimension (related to others). Several papers indirectly argue that introducing private gain or losses activates economic computation rather than moral decisions, so we observe more egoistic and opportunistic behaviors (e.g., Tenbrunsel and Messick, 1999).

Subjects invest more on average when they know in advance their inheritance from the past. Knowing the inheritance from the past can activate reciprocity or fix an anchor point, a reference for individual contributions, whereas in absence of such anchor point, the anchor can be fixed only on the initial endowment. Moreover, anchor points function only when participants knew them in advance. If they remain unknown at decision time, contributions are not affected by this inheritance.

From a policy point of view, our paper brings interesting insights about factors that can contribute to the success of environmental policies. In fact, we show that basically, it may be that people care more about future generations than about current ones; in this case, environmental policies should be labeled as addressing futures problems and individuals, rather than contemporaneous issues. This may be implied by the fact that most individuals consider current problems as imminent and unsolvable, whereas for future problems, there is still time to find optimal solutions, and they perceive their action as more useful. Also, in 
order to make these policies effective, general information should exist not only on their expected effects, but also on what we inherited from the past.

\section{References}

Alpizar, F., Carlsson, F., Johansson-Stenman, O., 2008, Anonymity, reciprocity, and conformity: Evidence from voluntary contributions to a national park in Costa Rica, Journal of Public Economics, 92 (5-6): 1047-1060.

Andreoni, J., Petrie, R., 2004, Public goods experiments without confidentiality: a glimpse into fundraising, Journal of Public Economics, 88 (7-8): 1605-1623.

Cadigan, J., Wayland, P.T., Schmitt, P., Swope, K., 2011, An experimental public goods game with carryover, Journal of Economic Behavior and Organization, 80: 523-531.

Chaudhuri, A., 2011, Sustaining cooperation in laboratory public goods experiments: A selective survey of the literature, Experimental Economics, 14, pp. 47-83.

Croson, R., 2007, Theories of commitment, altruism and reciprocity: Evidence from linear public goods games, Economic Inquiry, 45 (2): 199-216.

Hugh-Jones, D., Reinstein, D., 2011, The benefit of anonymity in public goods games, http://davidreinstein.files.wordpress.com/2011/05/secret_santa_experiment_may.pdf

Holt, C., 2007, Markets, Games, and Strategic Behavior. Pearson Education, Inc., p 167-80.

Kivetz, Y., Tyler, T.R., 2007, Tomorrow I'll be me: The effect of time perspective on the activation of idealistic versus pragmatic selves. Organizational Behavior and Human Decision Processes, 102: 193-211.

Ledyard, J.O., 1995, Public good: A survey of experimental research. In The Handbook of Experimental Economics; Kagel, J.H., Roth, A.E., Eds.; Princeton University Press: Princeton, NJ, USA.

Rege, M., Telle, K., 2004, The impact of social approval and framing on cooperation in public good situations, Journal of Public Economics, 88: 1625-1644.

Rogers, T., Bazerman, M.H., 2008, Future lock-in: Future implementation increases selection of should choices, Organizational Behavior and Human Decision Processes, 106 (1): 1 - 20.

Tenbrunsel, A.E., Messick, D.M., 1999, Sanctioning systems, decision frames, and cooperation, Administrative Science Quarterly, 44: 684-707. 
Zauberman, G., Lynch, J.G., 2005, Resource slack and propensity to discount delayed investments of time versus money, Journal of Experimental Psychology: General, 134 (1): 23-37. 


\section{Appendix (on line only)}

\section{(Translated from the French instructions)}

\section{Instructions for Treatment T3}

\section{Screen 1}

Good morning.

Thank you for participating to this experiment. Please read with care these instructions. Should you have any question, please raise your hand and call the administrator.

Stay focused: do not use cellular phones or personal computers; otherwise you can be excluded from the experiment.

Payoffs are denominated in Experimental Currency Units (ECU). At the end of the experiment, the ECU will be converted in euros at the exchange rates $100 \mathrm{ECU}=1$ euros. The final gain can reach about 10 euros.

\section{Screen 2.}

The experiment involves 10 rounds. You will play 10 times the same game. You belong to a group of 5 anonymous players. The final payoff depends on your decision and the decision of the other players. Group composition changes at every round.

At the beginning of each round $t$ you get 40 ECUs. Each other member of your group gets 40 ECUs. In addition to this amount, you will receive a "bequest from the past". The amount depends on the rules defined in the next paragraph.

For each ECU that you invest in the public good at round $\mathrm{t}$, at round $t+1$ each other member of your new group but you will receive 0.5 ECU (each ECU you invest in the Public good brings a total of $2 \mathrm{ECU}$ to the four other members). At round $t$, you will benefit from the investment in public good of the members of your group at the previous round $t-1$. You can invest a maximum amount of 40 ECUs.

Your gain at each round is equal to 40 ECUs, less your investment, plus the total amount invested by the four other member of your group at $(t-1)$ divided by 2 . 
You will learn your gain for the round at the end of each round.

At the end of the experiment, the total game will be converted into euros and you will be paid anonymously and in cash.

\section{Screen 3.}

To make sure that you understood the rules, please answer these questions:

1. The investment in $t$ contributes to the wealth of the group members
A. At time $\mathrm{t}$
B. At time $\mathrm{t}-1$
C. At time $t+1$

2. At round $t$, each player in a group contributes 25 ECUs to the PG. At the past period, the same players have contributed 10 ECUs. The gain of a player for this round is:
A. $40-25+(25 \times 4) / 2$
B. $40+(25 * 5) / 2$
C. $40-25+(10 * 4) / 2$

\section{Screen 4.}

Correct answers are $1 \mathrm{~B}$ and $2 \mathrm{C}$

Screens 5 and 6 - to be repeated ten times.

\section{Screen 5. Decision}

Round Nb. 1 (... 10)

Your endowment is 40 ECUs

At Round 1 only: "Your bequest from the past is [A]" (depending on treatment, $A=0,40,80$ ).

Rounds 2 to 10 "The investment of your group member at time (t-1) brings you": [R]

Your contribution to the PG for this round is [v] ECUs.

Screen 6.Results.

Your endowment 40 ECUs 
Your investment in the PG is [v] ECUs

Round 1. "Your bequest from the past" is [A] ECUs, then, for Rounds 2 to 10, "The investment of you group member at time (t-1) brings you" [R]

Your gain for the round is $[\mathrm{y}][=40-\mathrm{z}+\mathrm{A}($ or $\mathrm{R})]$. 
ESSEC Business School Avenue Bernard Hirsch BP 50105

95021 Cergy-Pontoise Cedex France

Tél. +33(0)134433000

$\mathrm{Fax}+33(0) 134433001$

www.essec.fr

\section{ESSEC Executive Education} CNIT BP 230

92053 Paris-La Défense France

Tél. +33(0)146924900

Fax +33(0)1 46924990

http://formation.essec.fr

ESSEC Business School

Singapore Campus

100 Victoria Street

National Library Building \# 13-02

Singapore 188064

essecasia@essec.fr

Tél. +6568849780

Fax +6568849781

www.essec.edu

Informations

Alison Boug

+33 (0)134433358

bougi@essec.fr

www.essec.fr

research.center@essec.fr

ISSN 1291-9616 